\title{
An analysis based on a special hard landing incident
}

\author{
Chun Wang ${ }^{\mathrm{a}}$, Lingyun Miao ${ }^{\mathrm{b}}$, Huabo Sun ${ }^{*}$ \\ China Academy of Civil Aviation Science and Technology, Beijing, 100028, P.R.China \\ email:wangchun@mail.castc.org.cn
}

Keywords: hard landing, vertical acceleration, nose gear, incident

\begin{abstract}
As part of a study on flight safety, this article introduces the profile of the Chinese civil aircraft hard landing primarily. And then, discusses the special circumstance of the hard landing through an analysis of some flight incident, which needs to pay special attention. The data in the flight data recorder (FDR) doesn't show how deep of the damages to aircraft which caused by hard landing. This situation may cause security risks. This article has played a warning role for security risks.
\end{abstract}

\section{Introduction}

Small occurrence and mortality are characteristics of civil aviation accidents. Because of its extensive social influence, 'aviation security' is an very important indicator of the civil aviation. From 1996 to 2005, there were about 200 accidents happened worldwide, according to global accident statistics of Flight Safety Foundation (FSF) and Boeing. Most accidents happened in approach and landing phases, although it account for only 4 per cent of the flight time, it account for up to 59 per cent (118 accidents) of all cases [1].

In the aeronautical world, referring to 'hard landing', there is a convention established by usage: when an aircraft is landing, it seems like a brick "hits" the airstrip. Actually, there is a clear sense from the strike on the bottom [2]. In this case, there is a definition of 'hard landing' in Maintenance handbook of A320 from Boeing [3-5]. When the aircraft is landing, the vertical acceleration exceeds the predetermined limit, or the speed in the vertical direction exceeds a predetermined value. As the aircraft landing, there is an instant impact load working on the landing gear, wing and body. And this is what we called hard landing incident. However, due to the deformed or damaged mechanical parts, it is easily damage the main landing gear. And takeoff and landing phase is also an accident-prone stage. So hard landing incident response seriously affects aircraft takeoff and landing performance.

Mentioned in the A320 Maintenance Manual [6], hard Landing is different from the overweight landing, it is based on the flight recorder system recording touchdown, aircraft center of gravity is to bear vertical acceleration exceeds $2.6 \mathrm{~g}$ or vertical speed is greater than $540 \mathrm{fpm}$. The data should reflect the performance requirements of the aircraft from the vertical acceleration, which is the limit of endurance aircraft structure. Aircraft manufactures believe that a hard landing can cause structural damage to the wings and landing gear, engine and even rupture. 'Hard landings' do not cause more casualties, but will cause structural damage to the airframe, landing gear and the like. According to statistics, in the incident of landing, the 'Hard landing' accounted for $22 \%$.

\section{China's Overall Situation Overview}

In general, the determination method of hard landing is based on the pilots' feeling and aircraft recording parameter combination. So whether QAR (Quick access recorder) or FDR parameters are preserved is particularly important. Civil Aviation Administration of China(CAAC) issued the [Flight operational quality assurance (FOQA) Implementation and Management]'s Attachment1[Airbus series aircraft flight operational quality assurance programs and requirements]for large vertical acceleration at landing specified: Slight deviation $>1.60 \mathrm{gn}$, serious

Corresponding author ${ }^{*}$ :sunhb@castc.org.cn 
deviation>1.80gn (gn is the standard acceleration of free fall); Attachment1[Boeing series aircraft flight operational quality assurance programs and requirements] for large vertical acceleration at landing specified: Slight deviation $>80 \%$ of the aircraft structure inspection gn, serious deviation $>$ $90 \%$ of the aircraft structure inspection gn.

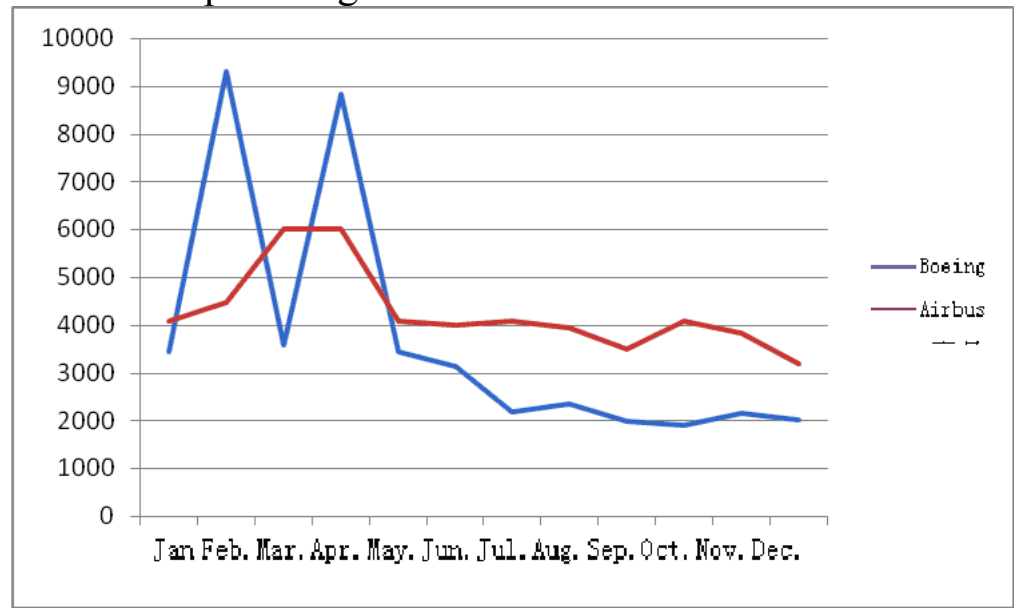

Fig. 1. China's major airlines of Airbus and Boeing serious incidents per month in 2013

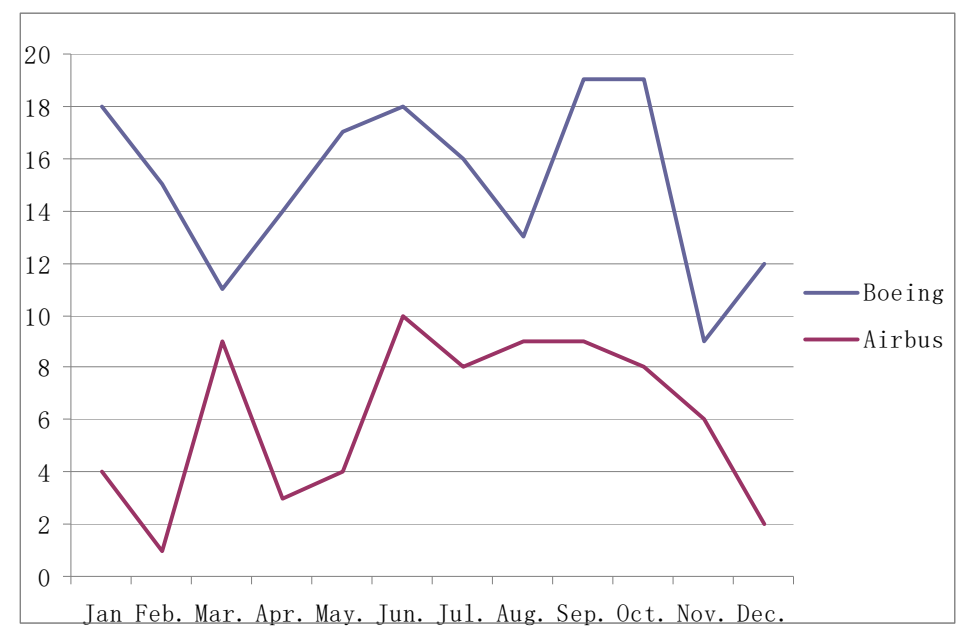

Fig. 2. China's major airlines of Airbus and Boeing hard landing serious incidents per month in 2013

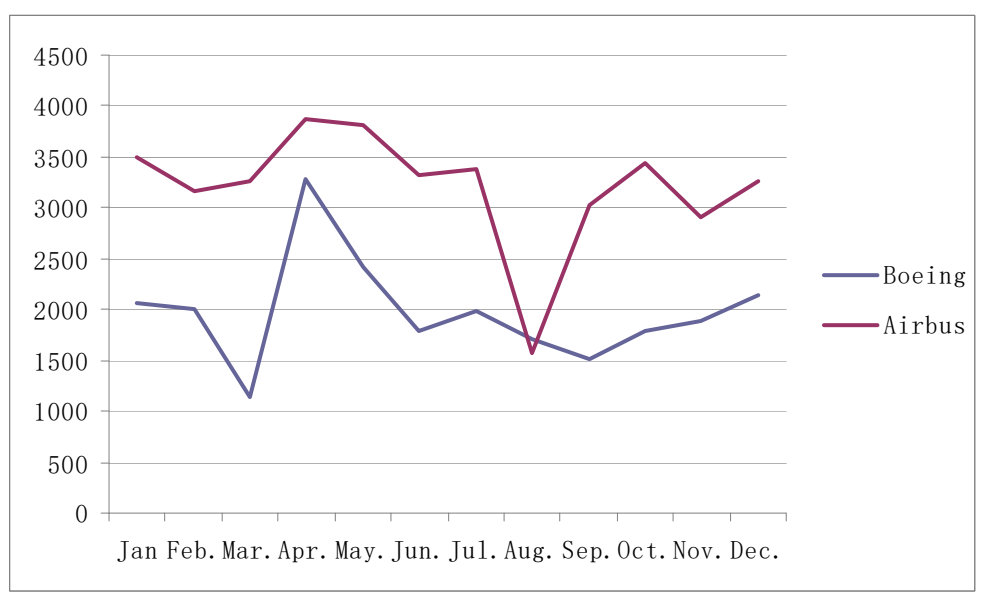

Fig. 3. China's major airlines of Airbus and Boeing serious incidents per month in 2014 


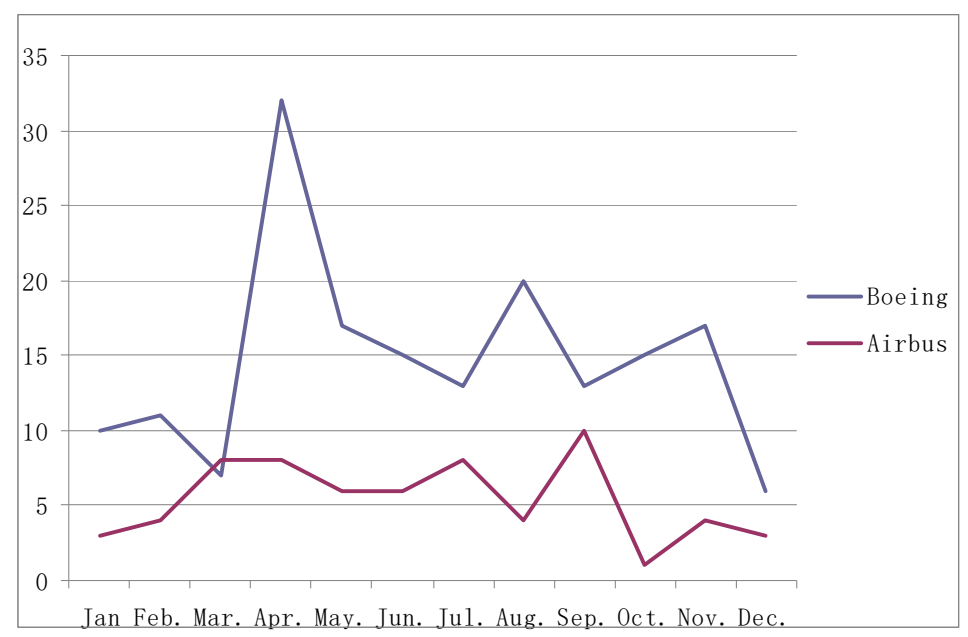

Fig. 4. China's major airlines of Airbus and Boeing hard landing serious incidents per month in 2014[7]

Fig. 1 and Fig. 2 shows the counts of incident and hard landing per month in 2013. The date shows a great fluctuating range of incidents, but the incidents caused by hard landing keeps relatively steady.

Fig. 3 and Fig. 4 shows the counts of incident and hard landing per month in 2014. The data shows the same feature compared with Fig.1 and Fig.2.

From the above analysis, the incidents caused by hard landing were relatively less, and the pilots are relatively cautious to its consequences in China.

It's important to note that it is hard to quantify pilots' subjectivities. So companies mainly rely on record the parameters of QAR or FDR. But, the parameters may have some distortions.

\section{Force analysis about landing gear}

By the dividing points of the grounding moment of the main landing gear (MLG) and nose landing gear (NLG), the flight landing can be divided into two stages: two gear landing and three gear landing. In fact, two gear landing can also be divided into two ways: symmetric landing and asymmetric landing. While the symmetrical landing is about the main landing gears landing simultaneously, the asymmetrical landing is about the main landing gears landing asynchronously, and this is the common case.

The landing loads are probably from two parts: Wing root load and landing gear load. As for the normal landing, at the moment of grounding, ideally, the lift approximately equals to the gravity of the aircraft, and the lift rate is about zero, while the proportion of the load is close to 1[8-9].

The equation of motion in the vertical direction of the two points landing phase is:

$$
F_{s} \cos \alpha=\frac{1}{2}(W-m z)
$$

In the equation, $z$ is the vertical acceleration, $F_{s}$ is the buffering force on the aircraft, $\alpha$ is the angle between fuselage reference line and the ground, $W$ is the equivalent weight of aircraft including integrated lift, $m$ is the quality of the entire aircraft. Predictably, the overload of instantaneous vertical velocity (IVV) and vertical acceleration can cause hard landing.

Asymmetric landing is main gear landing successively. Most landing is asymmetric landing. Fig. 5 and Fig. 6 show a side view and a front view of asymmetric landing. During the movement process, firstly is single point landing, and then the two points landing.

The equation of motion in the vertical direction of the single points landing phase is:

$$
F_{s_{-} m 1} \cos \beta \cos \alpha=W-m z
$$

The overload of instantaneous vertical velocity (IVV) and vertical acceleration can cause hard landing of single landing gear. 
To analyze the asymmetric landing, when the roll angle $\beta$ is too large, the lateral load $F_{s_{-} m l} \sin \beta$ will be overload. As the designing loading direction is axial load, the overload of lateral load can cause hard landing.

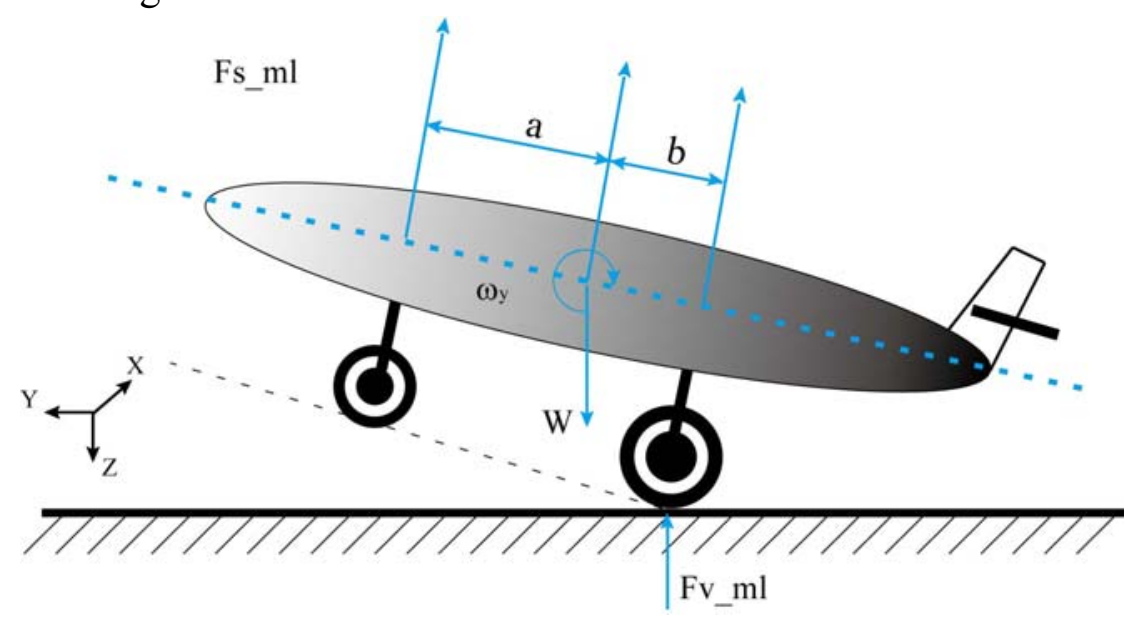

Fig. 5. Side view of asymmetric landing

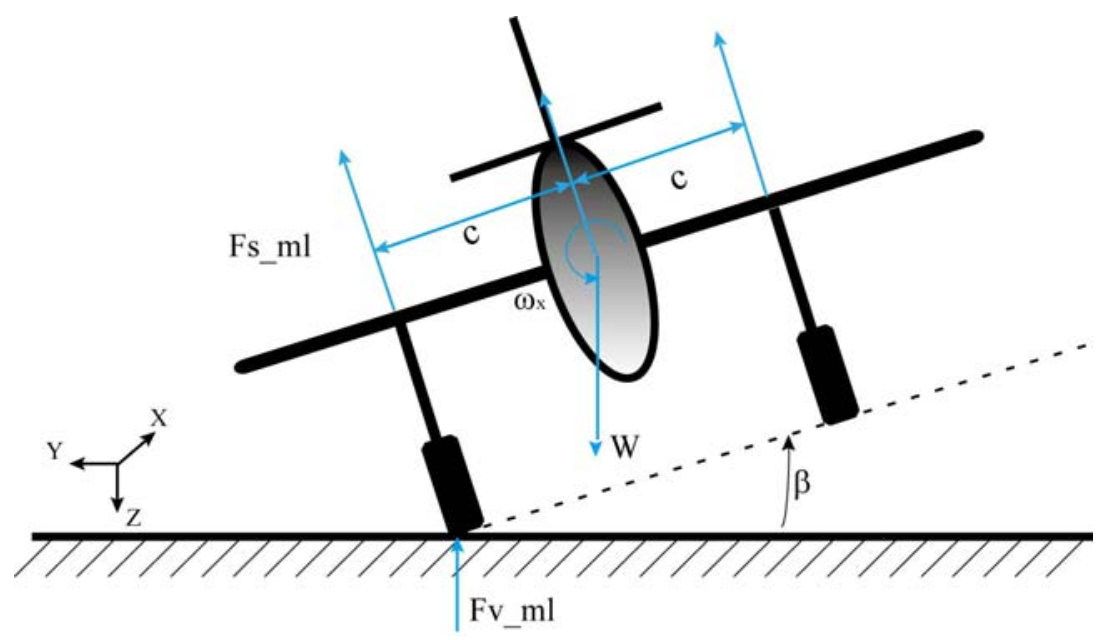

Fig. 6. Front view of asymmetric landing

\section{Special Incident Analysis}

In 2011, damage to the aircraft an airline incident occurred during landing. Airlines XX's XXXX aircraft performing flight XXXX, during landing at XX airport, as a result of an improper operation, the aircraft had twice jumps. Further in the correction phase, due to lack of crew situational awareness in decision making and experiences of, stall protection, Nose Gear damage was serious, and aircraft was unable Self-detachment, and the airport was temporarily closed.

After that, the airport units performed a check-out to confirm no extraneous matter on the airstrip or airstrip lighting. The aircraft occurred two jump during three times landing, the first Touch Down Point(TDP) in the vicinity aiming point was from the airstrip ending $420 \mathrm{M}$, the second TDP was from the first TDP $136.4 \mathrm{~m}$, the third TDP was from the second TDP $76 \mathrm{~m}$. 


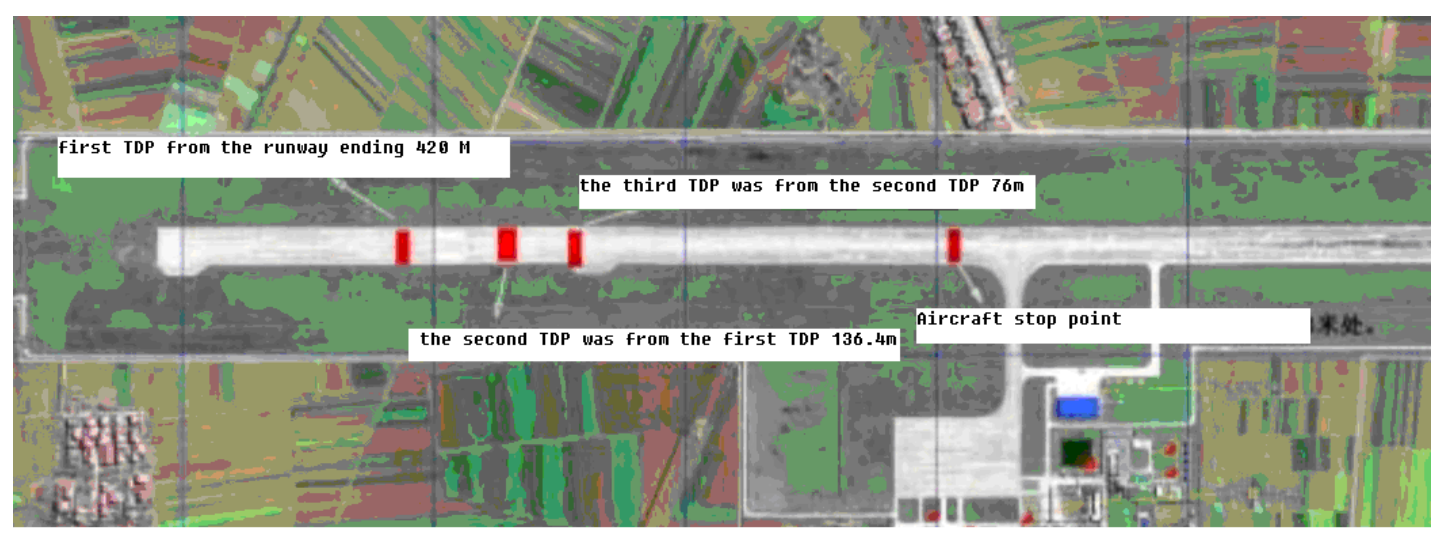

Fig. 7. Aircraft landing location

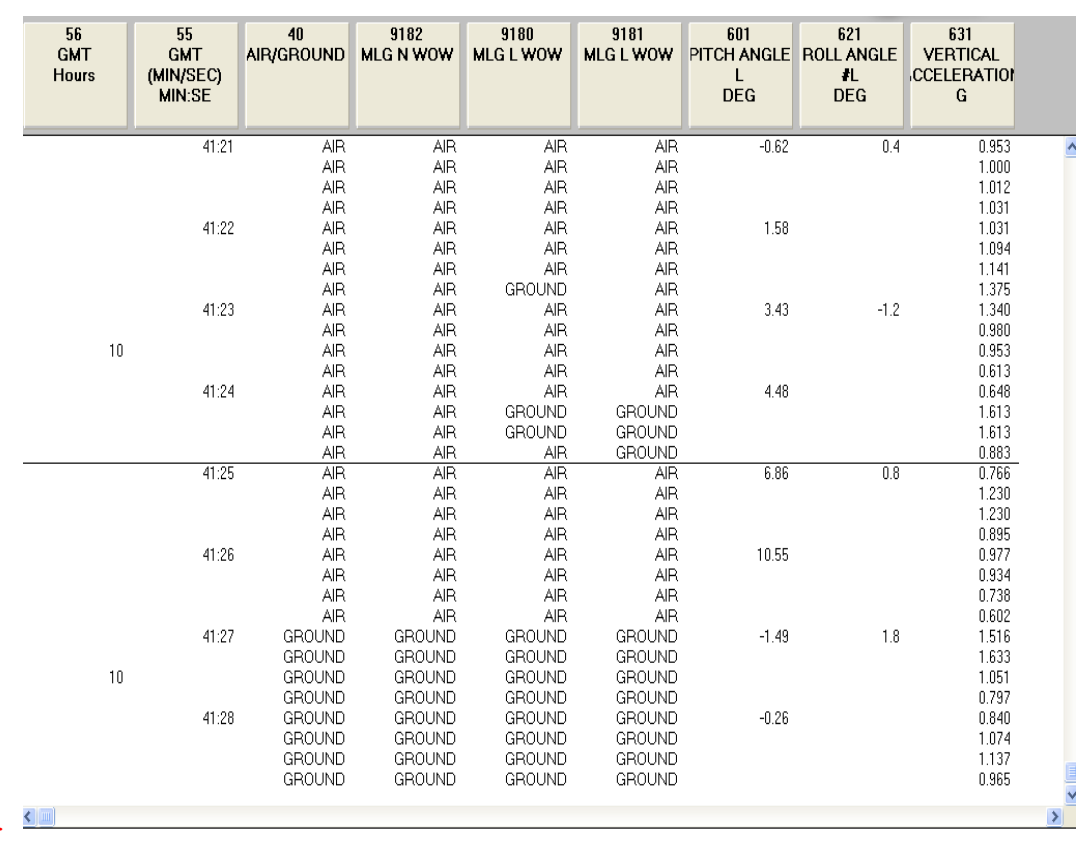

Fig. 8. Major data of FDR-1

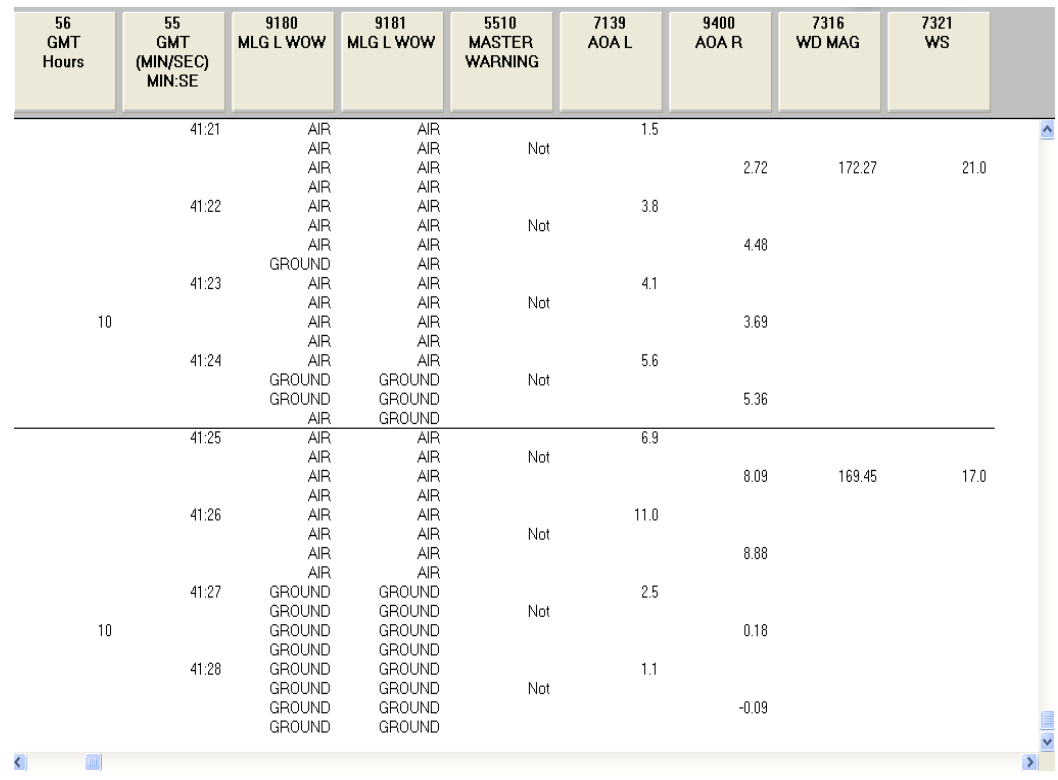

Fig. 9. Major data of FDR-2

From Fig.8 and Fig.9,we know that when the First TDP, left main gear grounded first, vertical 
acceleration was $1.375 \mathrm{~g}$, pitch angle was $1.58^{\circ}$, roll angle was $-1.2^{\circ}$, aircraft bounced after approximately $0.25 \mathrm{~s}$, stayed in the air for about $1.5 \mathrm{~s}$. Then the Second TDP, two main gears grounded at same time, vertical acceleration was $1.613 \mathrm{~g}$, pitch angle was $4.48^{\circ}$, roll angle was $0.8^{\circ}$, aircraft bounced after approximately $0.7 \mathrm{~s}$, stayed in the air for about $2.25 \mathrm{~s}$. during the Third TDP, nose gear and two main gears grounded at same time, vertical acceleration was $1.633 \mathrm{~g}$, pitch angle was- $1.49^{\circ}$.The sink rate were $396 \mathrm{ft} / \mathrm{min}, 296 \mathrm{ft} / \mathrm{min}, 17 \mathrm{ft} / \mathrm{min}$ in turn.

From the data, we could see a relatively landing heavy, but it should not have too much damage technically. in the model monitoring standard for large vertical acceleration about jumping landing in this airline, there is following requirements: the vertical acceleration, The first TDP $\geq 1.80 \mathrm{~g}$; The second TDP $\geq 1.50 \mathrm{~g}$, lasting longer than $1 \mathrm{~s}$. As can be seen from the data vertical load only slightly larger than a standard monitor when the second TDP, the aircraft should not cause too much harm.

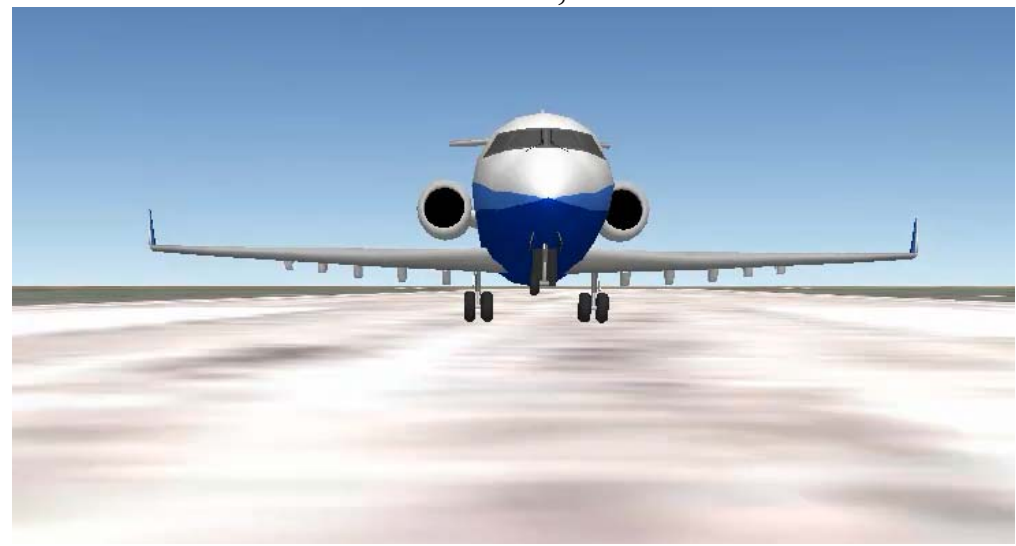

Fig. 10. the simulation of phases of landing -1

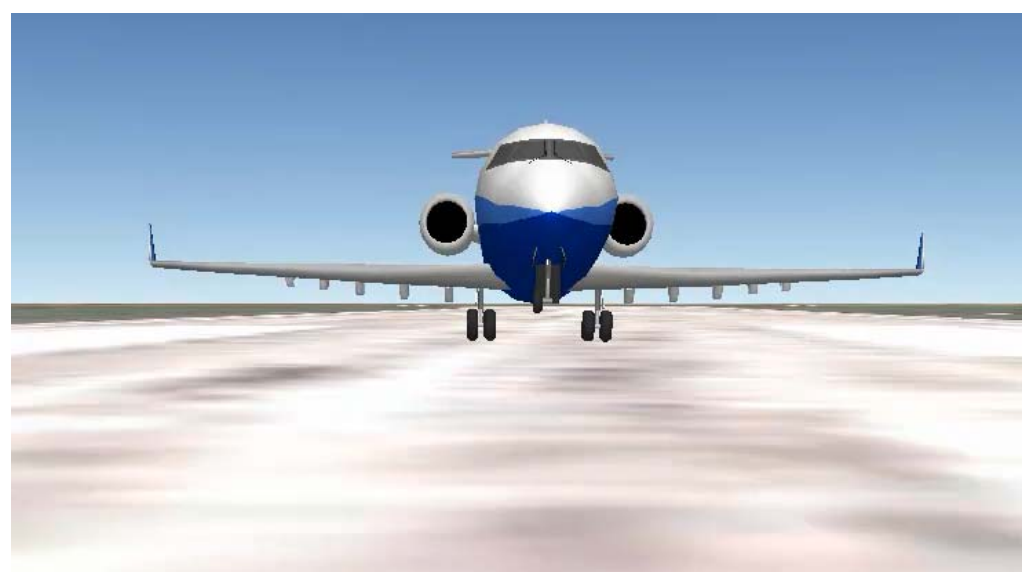

Fig. 11. the simulation of phases of landing -2

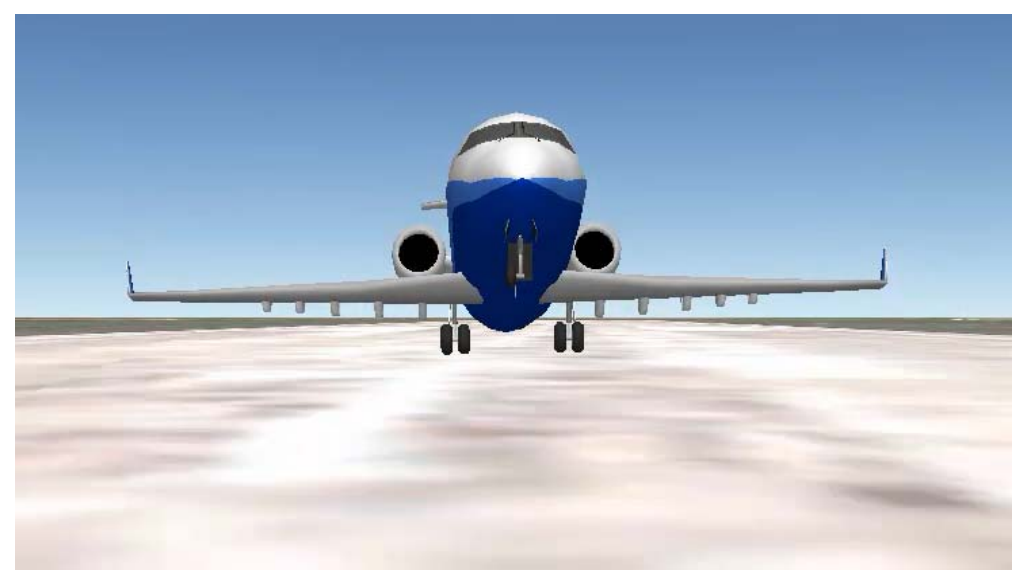

Fig. 12. the simulation of phases of landing -3 


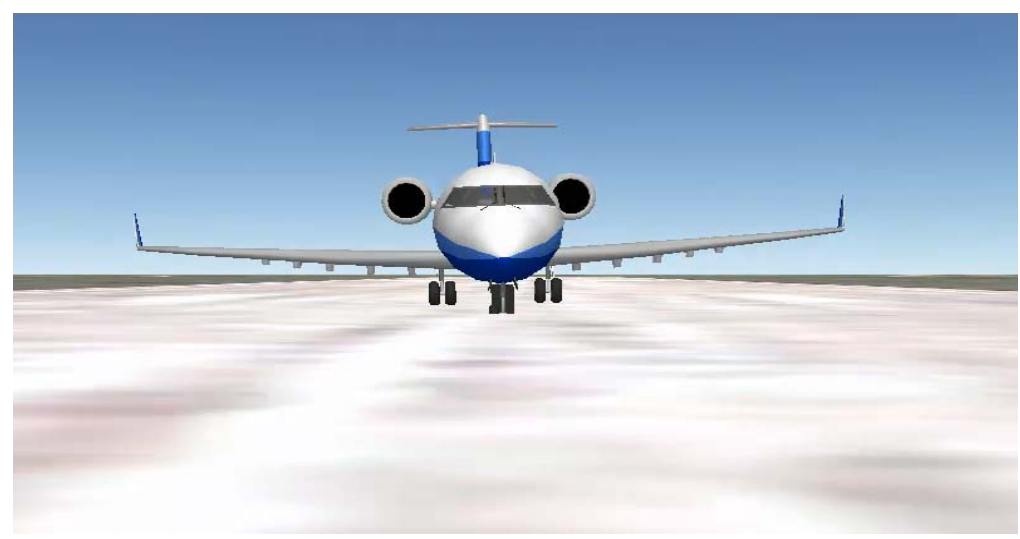

Fig. 13. the simulation of phases of landing -4

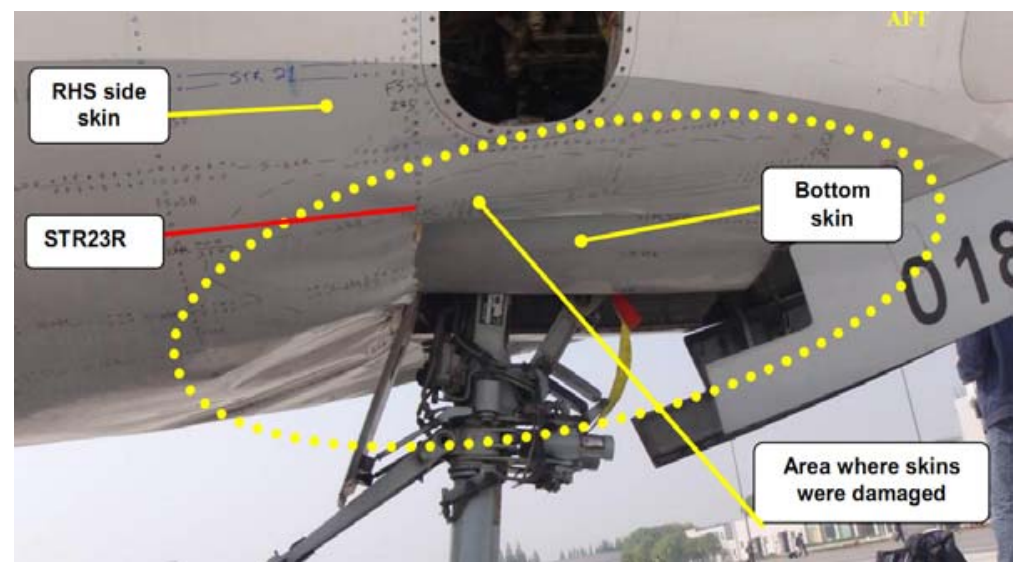

Fig. 14. the aircraft damage points-1

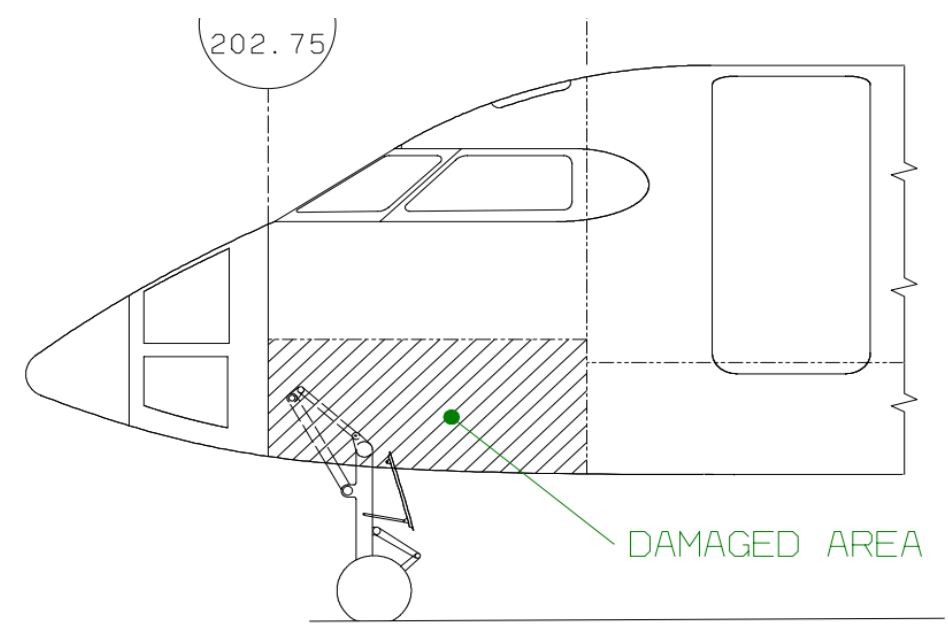

Fig. 15. the aircraft damage points-2

Fig.10-Fig.13 is simulation diagram of the aircraft landing phases. We can see that before aircraft main gears grounded, the nose gear had a rise and then fell in the process. At this process, the nose gear and its support system withstand tremendous forces. This led to the destruction regional as shown in Fig.14 and 15 near the nose gear. The three vertical accelerations were not serious, but after analysis we found other factors that show the pitch angles are $1.58{ }^{\circ}$ and $4.48^{\circ}$ in first and second TDP, the third is $-1.49^{\circ}$. Pitch angles of the first two are in the normal range of the model to monitor standards. The third is showing a small pitch angle. Before a second the third landing, pitch angle increased to $10^{\circ}$. When the third occurred, the pitch angle was mutant to $-1.49^{\circ}$. Pitch angle changing so large, pressure by nose gear in the third TDP can be imagined, but we see is slightly larger than the models on this parameter monitoring standards typical incident criteria $(1.60 \mathrm{~g})$ from data. 
There were obvious data discrepancies between FDR data and realistic status. The factors are aircraft internal construction and the position of detection instruments. This is because the instruments measured three direction of the acceleration is an accelerometer. The aircraft accelerometer present in inertial navigation system (INS). as usual, INS is installed in the avionic compartment of the aircraft, estimated the aircraft's inertial navigation parameters as a whole, and that does not directly make acceleration from the nose gear reflected in the data records. That means vertical load value recorded on the flight recorders of the aircraft is as a whole bear, rather than damaged area is exposed. It can be seen from this incident, if you just look at the vertical load, it can cause false positives. By that, if the consequences were not so serious incident, the airline is determined whether or not by checking it by the monitoring data. Then the result maybe doesn't need to check it. That will make the aircraft not to be safe. It is only hope that the next checking or pilot's personal feelings, which will result the development of unpredictable. That can be another choice.

Besides, underlying hard landing and other similar incidents can be greatly reduced by improve the measurement accuracy.

\section{Conclusion}

'Hard landing' affects the flight safety seriously. With the analyze of a special hard landing incident, and the comparison with FDR data and actual condition, this assay focuses on deficiencies in the current methodologies for detect hard landing, shows the hard landing conditions of major domestic airlines in the past two years. Moreover, presents some suggestions to reduce security risks.

\section{Acknowledgement}

The work presented in this paper is supported by NSFC (National Natural Science Foundation of China) (ID: U1333124 \& U1533102).

\section{References}

[1] Aviation Safety: U.S. Efforts to Implement Flight Operations Quality Assurance [J]. FlightSafety Digest, 1998.

[2] Liu Qinggui,How to avoid 'hard landing', The captain talk about aircraft,2014

[3] Boeing737 Aircraft maintenance manual[z]. Boeing companyt, 2006.

[4] B737Operations manual[z]. Boeing company, 2006.

[5] A320 / A321 Aircnft Maintenance Manual[Z]. Airbus Industry, 2003.

[6] Talk about hard landing and landing jump of A320, Civil Aviation Resource Net Of China

[7] Data from the China Academy of Civil Aviation Science and Technology

[8] Shu Ping, Wang Xuhui, Huang Shengguo and Liu Yongjian. Research on hardlanding with reaction of civil aircraft based on multiparameter, MachineDesign and Manufacturing Engineering,2009

[9] .Airplanes Statistical Summary of Commercial Jet Airplane Accidents Worldwide Operations 1959 -2005[Z],Statistical Summary Boeing Company, 2006.5. 